\title{
Skin-friction Measurements in Turbulent Boundary Layers
}

\author{
Cristian Rendon-Cardona ${ }^{\# 1}$, Zhoushun Ruan ${ }^{\dagger 2}$, Oscar Ruiz-Salguero ${ }^{\# 3}$

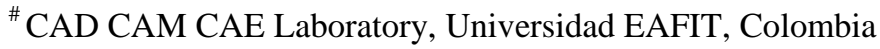 \\ ${ }^{\dagger}$ Walter Bassett Aerodynamics Laboratory, The University of Melbourne, Australia \\ ${ }^{1}$ crendo11@eafit.edu.co \\ 2 zruan@student.unimelb.edu.au \\ 3 oruiz@eafit.edu.co
}

\begin{abstract}
In the context of measurements in the boundary layer, the problem of estimating the skinfriction velocity is relevant because this velocity is proportional to the drag force and therefore is related to the energy wasted by friction in vehicles such as planes, cars, ships, etc. The existing literature is scarce when presenting an overview of the methods appropriate for the estimation in the scenario: (a) flat plate flow, (b) air incompressible regime, (c) outdoor conditions, (d) turbulent flow. As a response to such shortcomings, this manuscript presents an overview of the methods: (1) hot-wire anemometry, (2) hotfilm anemometry and (3) particle image velocimetry (PIV), in the aforementioned scenario. This manuscript reviews the diverse components that these methods require and contrasts the skin-friction velocity measurements stemming from them. Our results show a consistent estimation of the skin-friction velocity with the three methods. Future work is required in assessing the influence of wall proximity on hot-wire measurements and the influence of different Reynolds regimes on the skin-friction velocity estimations. Future work is required in the aspects of comparing the direct measurement of the skinfriction velocity with the hot-wire probe very close to the wall and the assessment of the accuracy of the techniques at different Reynolds numbers.
\end{abstract}

Keyword-Skin-friction, Boundary Layer, Hot-wire, Hot-fil, Turbulent Flow

\begin{tabular}{|c|c|c|}
\hline \multirow[b]{2}{*}{$U_{\infty}$} & \multicolumn{2}{|l|}{ GLOSSARY } \\
\hline & Free-stream velocity & $\mathrm{m} / \mathrm{s}$ \\
\hline$\delta$ & Boundary layer thickness & $\mathrm{m}$ \\
\hline$v$ & Kinematic viscosity & $\mathrm{m}^{2} / \mathrm{s}$ \\
\hline$\ell$ & Viscous length scale & non-dimensional \\
\hline+ & Viscous scaled parameters & non-dimensional \\
\hline$U_{\tau}$ & Friction velocity & $\mathrm{m} / \mathrm{s}$ \\
\hline$C_{f}$ & Friction coefficient & non-dimensional \\
\hline$x$ & Stream-wise coordinate & $\mathrm{m}$ \\
\hline$y$ & Span-wise coordinate & $\mathrm{m}$ \\
\hline$z$ & Wall-normal coordinate & $\mathrm{m}$ \\
\hline$U$ & $\begin{array}{l}\text { Streamwise component }(x) \text { of the } \\
\text { velocity }\end{array}$ & $\mathrm{m} / \mathrm{s}$ \\
\hline$W$ & $\begin{array}{l}\text { Wall-normal component }(z) \text { of the } \\
\text { velocity }\end{array}$ & $\mathrm{m} / \mathrm{s}$ \\
\hline $\bar{U}_{M}$ & $\begin{array}{l}\text { Matrix with average statistics of the } \\
\text { stream-wise component }\end{array}$ & $\mathrm{m} / \mathrm{s}$ \\
\hline$\overline{\boldsymbol{W}}_{M}$ & $\begin{array}{l}\text { Matrix with the average statistics of } \\
\text { the wall-normal component }\end{array}$ & $\mathrm{m} / \mathrm{s}$ \\
\hline $\bar{U}$ & $\begin{array}{l}\text { Average statistics of the stream-wise } \\
\text { component }\end{array}$ & $\mathrm{m} / \mathrm{s}$ \\
\hline $\bar{W}$ & $\begin{array}{l}\text { Average statistics of the wall-normal } \\
\text { component }\end{array}$ & $\mathrm{m} / \mathrm{s}$ \\
\hline$t_{s}$ & Sampling time & $\mathrm{s}$ \\
\hline$\Delta f$ & Sampling frequency & $\mathrm{Hz}$ \\
\hline$R e_{\tau}$ & Frictional Reynolds number & non-dimensional \\
\hline
\end{tabular}




$\begin{array}{cl}C_{\text {pre }} & \text { Pre-calibration curve for hot-wire } \\ C_{\text {post }} & \text { Post-calibration curve for hot-wire } \\ C_{m} & \text { Measurement curve for hot-wire } \\ \text { PIV } & \text { Particle Image Velocimetry } \\ \text { FOV } & \text { Field of View } \\ n x & \text { Number of points in the stream-wise direction } \\ n z & \text { Number of points in the wall-normal direction } \\ \text { NFrames } & \text { Number of snapshots } \\ \text { CTA } & \text { Constant Temperature Anemometer } \\ \text { MUCTA } & \text { Melbourne University Constant Temperature Anemometer } \\ \text { HRNBLWT } & \text { High Reynolds Number Boundary Layer Wind Tunnel }\end{array}$

\section{INTRODUCTION}

Turbulence is a chaotic and unpredictable phenomenon which presents challenges when it's necessary to make measurements. In this work, we assess skin-friction measurements inside the boundary layer in: (a) flat plate flow, (b) air incompressible regime, (c) outdoor conditions, (d) turbulent flow. The skin-friction velocity is a form to express the shear stress in velocity units, directly relating velocities in the flow with the shear stress and, therefore, drag. Measuring the skin-friction is crucial in many aspects, ranging from the detection of the influence of roughness in the drag of a ship and the evaluation of active flow control techniques that intend to reduce drag.

The measurement of the skin-friction is executed in two ways. Indirectly calculation from measurements of the boundary layer velocity profile and direct measurements in the wall or very close to the wall. This manuscript presents an overview of methods (a) hot-wire anemometry, (b) hot-film anemometry and (c) Particle Image Velocimetry (PIV).

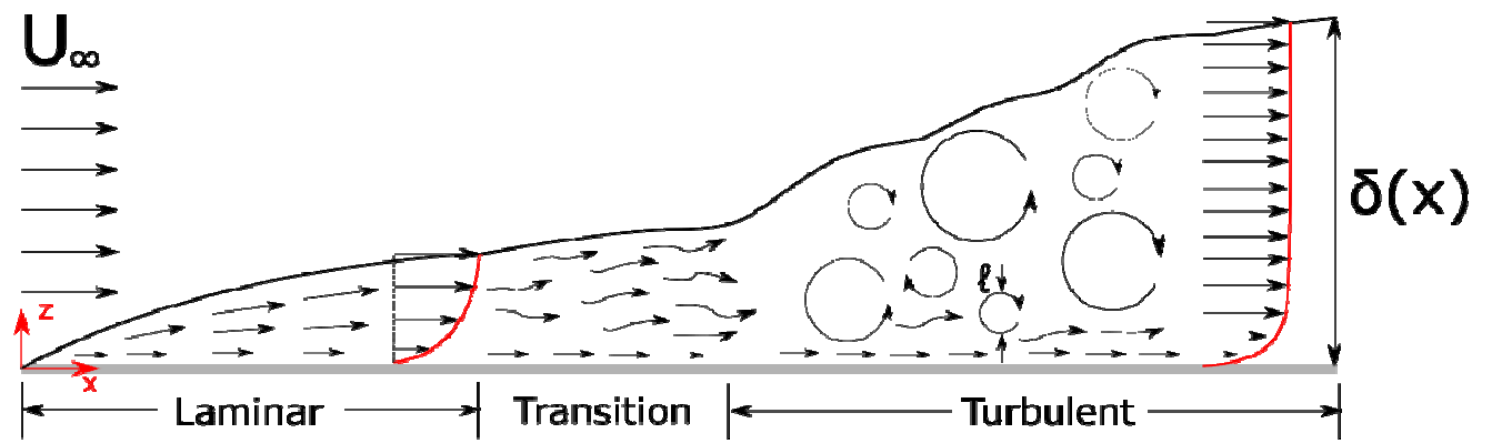

Fig. 1. Development (laminar to turbulent) of boundary layer over a flat plate. Red line: velocity profile. $\delta(x)$ : boundary layer thickness at $x$.

Measurements are conducted within the boundary layer, where viscosity has influence in the flow and skinfriction velocity can be directly measured or estimated from the velocity profile.

The wall-normal position $z$ and the stream-wise velocity $\bar{U}$, are scaled by the skin-friction velocity as follows:

$$
z^{+}=\frac{z U_{\tau}}{v} \quad \bar{U}^{+}=\frac{\bar{U}}{\boldsymbol{U}_{\tau}}
$$

By scaling the stream-wise velocity and the wall-normal position by the skin-friction velocity, any nonperturbed boundary layer will collapse into the same profile. Fig. 1 illustrates the profile and Eq. (1) the relation between the profile and the skin-friction.

Other important quantity to introduce is the friction Reynolds number, which is a Reynolds number expressed in terms of the friction velocity $U_{\tau}$, the boundary layer thickness $\delta$ and the viscosity $v$. The $R e_{\tau}$ describes the type of flow occurring in the boundary layer.

$$
R e_{\tau}=\frac{U_{\tau} \delta}{v}
$$

\section{LITERATURE REVIEW}

The measurement of the skin-friction velocity can be carried on in two ways, (1) directly measuring the skinfriction with floating elements or flush-mounted constant temperature anemometer techniques, and (2) indirectly computing the skin-friction from boundary layer velocity measurements. 


\section{A. Direct Methods}

Ref. [1] utilizes flush-mounted hot-wire anemometers to directly measure the skin-friction velocity in laminar-turbulent transition flow (low Reynolds numbers). The wire was capable of measuring the fluctuations in the skin-friction with high quality signal but presents a higher application effort.

Ref. [2] presents an alternative for the floating element technique with a custom build force transducer and data acquisition system. The authors directly measure the skin-friction friction coefficient $\left(C_{f}\right)$ trying to reduce the signal-noise ratio.

Ref. [3] implements active flow control to reduce skin-friction velocity over a flat plate. The authors perturb the boundary with jets injecting air in cross flow with the boundary layer. The skin-friction measurement is executed with flush-mounted hot-film anemometers since it is not possible to be estimated from the perturbed boundary layer profile.

\section{B. Indirect Methods}

Ref. [4] evaluates the viability of different techniques of measuring flow velocity for application on pedestrian level wind conditions. Their work focuses on techniques for measuring flow velocity the accuracy and cost of the techniques.

Ref. [5] compares different indirect methods to estimate the skin-friction velocity. the author introduces a methodology to estimate the skin-friction from velocity measurements.

Ref. [6] Evaluates a technique for high spatial range PIV measurements in the boundary layer and compares the results with previous hot-wire data. The high magnification cameras allow to measure close to the wall and directly compute the skin-friction velocity.

Ref. [7] assesses the accuracy of hot-wire anemometry. Conducting measurements very close to the wall inside the viscous sublayer. This approach also works for perturbed boundary layers but presents difficulties to measure near the wall at high Reynolds numbers.

TABLE I. Different Approaches for Measuring the Skin-friction Velocity.

\begin{tabular}{|l|l|l|l|}
\hline Approach & Refs. & Advantages & Disadvantages \\
\hline $\begin{array}{l}\text { Directly measurement of } \\
\text { the skin-friction velocity. }\end{array}$ & $\begin{array}{l}{[2],[3],} \\
{[8],[1],[9]}\end{array}$ & $\begin{array}{l}\text { (1) The measurements do } \\
\text { no depend on the boundary } \\
\text { layer profile. }\end{array}$ & $\begin{array}{l}\text { (1) Floating elements present low } \\
\text { signal-to-noise ratio. } \\
\text { (2) Accuracy is affected at very } \\
\text { low or very high Re }\end{array}$ \\
\hline $\begin{array}{l}\text { Indirect calculations of } \\
\text { the skin-friction. }\end{array}$ & $\begin{array}{l}{[7],[5],} \\
{[10],[4],} \\
{[6]}\end{array}$ & $\begin{array}{l}\text { (1) Work properly for low } \\
\text { and high Reynolds } \\
\text { numbers. }\end{array}$ & $\begin{array}{l}\text { (1) The boundary layer cannot be } \\
\text { perturbed. }\end{array}$ \\
\hline
\end{tabular}

Table II presents the typical [11] equipment used in the measurements by each technique. Materials and hardware are listed. Since PIV is a non-invasive measurement, it has not probe information in the table.

TABLE II. Each Column Presents the General Requirements for Each Measurement Method.

\begin{tabular}{|l|l|l|l|}
\hline & Hot-wire & Hot-film & PIV \\
\hline Probe Material & $\begin{array}{l}\text { - Tungsten } \\
\text { - Platinum } \\
\text { - Platinum-Iridium }\end{array}$ & $\begin{array}{l}\text { - Tungsten } \\
\text { - Platinum } \\
\text { - Platinum-Iridium }\end{array}$ & N/A \\
\hline $\begin{array}{l}\text { Probe } \\
\text { Dimensions }\end{array}$ & $\begin{array}{l}\text { - Diameter } 1-10 \mu m \\
\text { - Length: } 0.5-2 ~ m m\end{array}$ & - Thickness. 1 - $50 \mu m$ & N/A \\
\hline Hardware & $\begin{array}{l}\text { - Constant temperature } \\
\text { anemometer control system } \\
\text { - Analog-Digital Sampling } \\
\text { system }\end{array}$ & $\begin{array}{l}\text { - Constant temperature } \\
\text { anemometer control system } \\
\text { - Analog-Digital Sampling } \\
\text { system }\end{array}$ & $\begin{array}{l}\text { - High resolution } \\
\text { cameras } \\
\text { - High Power laser } \\
\text { - Synchronizer }\end{array}$ \\
\hline $\begin{array}{l}\text { Measurement } \\
\text { domain }\end{array}$ & - Point & - Point & - Plane \\
\hline
\end{tabular}

\section{Conclusions of the Literature Review}

Indirect methods for measuring the skin-friction are advantageous in their capability of measuring at different Reynolds numbers but depend on the non-perturbed boundary layer.

Direct methods are viable to measure in perturbed boundary layer but lose accuracy at very high or very low Reynolds numbers. 
This manuscript presents an overview of two indirect techniques and one direct method in the response of the lack of literature contrasting different methods the equipment used in the experiments and the measurement of the skin-friction velocity. The Clauser chart method ([12]) is used to estimate the skin friction from the indirect measurements.

\section{Methodology}

All the experiments were conducted in the High Reynolds Number Turbulent Boundary Layer Wind Tunnel (HRNBLWT) of Melbourne University, $21 \mathrm{~m}$ from the test section start. Fig. 2 presents a scheme of the facility.

Each measurement is carried on at a different free-stream velocity $U_{\infty}$ (i.e. different skin-friction Reynolds number $R e_{\tau}$ ). Table III exhibits the chosen $U_{\infty}$ and the approximated $R e_{\tau}$ for each measurement technique.

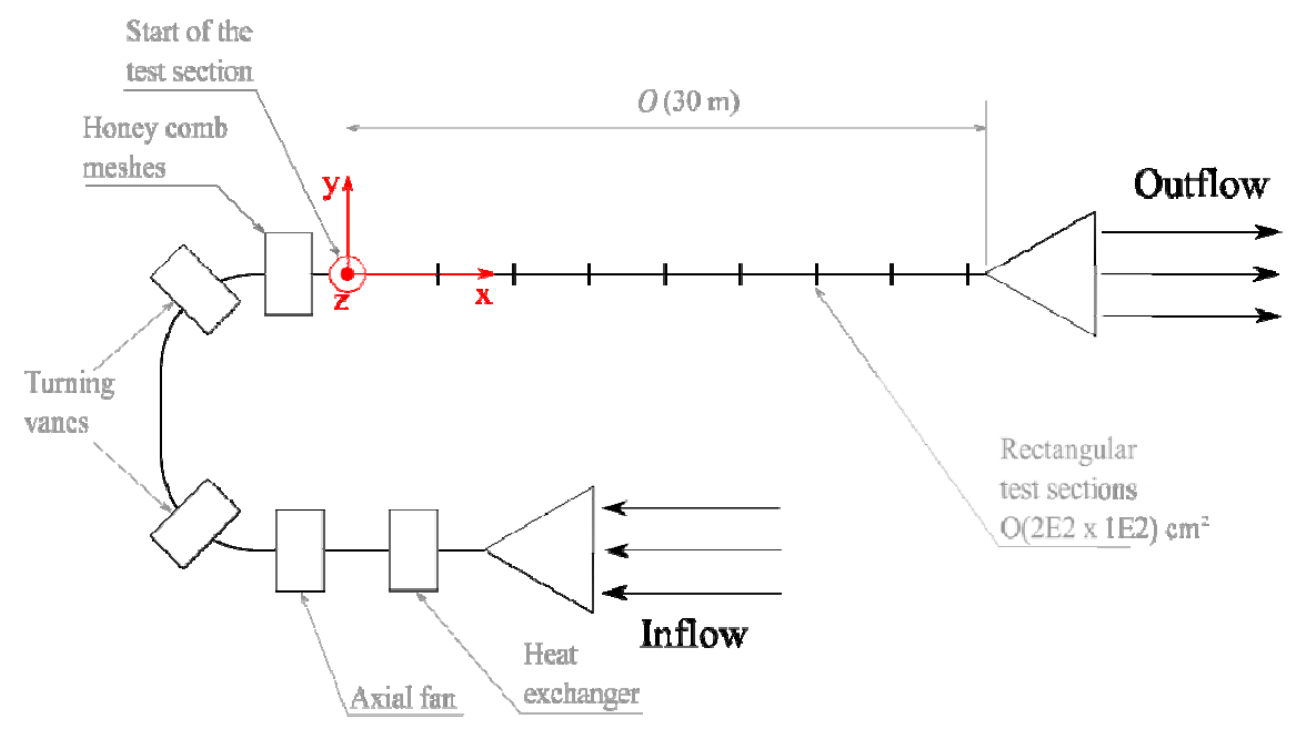

Fig. 2. General scheme of wind tunnel HRNBLWT of Melbourne University where measurements were conducted.

TABLE III. Free Stream Velocities for the Experiments.

\begin{tabular}{|c|c|c|}
\hline Method & $\boldsymbol{U}_{\infty}$ & $\boldsymbol{R e}_{\boldsymbol{\tau}}$ \\
\hline PIV & $20 \mathrm{~m} / \mathrm{s}$ & 14000 \\
\hline Hot-wire & $20 \mathrm{~m} / \mathrm{s}, 15 \mathrm{~m} / \mathrm{s}$ & 14000,10000 \\
\hline Hot-film & $15 \mathrm{~m} / \mathrm{s}$ & 10000 \\
\hline
\end{tabular}

Table IV briefly presents the equipment employed on the three measurements techniques. All the systems were available in the Walter Bassett Aerodynamics Laboratory of Melbourne University.

TABLE IV. Experimental Set-up for the Current Measurements.

\begin{tabular}{|l|l|l|l|}
\hline & Hot-wire & Hot-film & PIV \\
\hline Probe Material & - Platinum & - Platinum & N/A \\
\hline $\begin{array}{l}\text { Probe } \\
\text { Dimensions }\end{array}$ & $\begin{array}{l}\text { - Diameter } 0.5 \mu \mathrm{m} \\
\text { - Length: } 1 \mathrm{~mm}\end{array}$ & $\begin{array}{l}\text { - Thickness. } 50 \mu \mathrm{m} \\
\text { - Area: }(0.9 \times 0.1) \mathrm{mm}^{2}\end{array}$ & N/A \\
\hline Hardware & $\begin{array}{l}\text { - Melbourne University } \\
\text { Constant Temperature } \\
\text { Anemometer (MUCTA) } \\
\text { - Analog-Digital }\end{array}$ & $\begin{array}{l}\text { - AA Lab Systems AN- } \\
\text { 1003 Constant } \\
\text { temperature anemometer } \\
\text { - Analog-Digital } \\
\text { Sampling system }\end{array}$ & $\begin{array}{l}\text { - High resolution DSLR } \\
\text { cameras } \\
\text { - Spectra Physics } \\
\text { Quanta-Ray PIV 400 } \\
\text { NG: YAG } \\
\text { - Synchronizer }\end{array}$ \\
\hline $\begin{array}{l}\text { Sampling } \\
\text { Frequency }\end{array}$ & $-20 \mathrm{kHz}$ & $-4 \mathrm{kHz}$ & N/A \\
\hline
\end{tabular}

Boundary layers present an internal structure which depends on the wall-normal position $z$. In the inner layer, viscosity has a significant effect on the flow over inertial forces. Meanwhile, in the outer layer, viscosity loses its influence, and the flow becomes inviscid. Fig. 3 represents the subdivisions of the boundary layer their governing equations. 


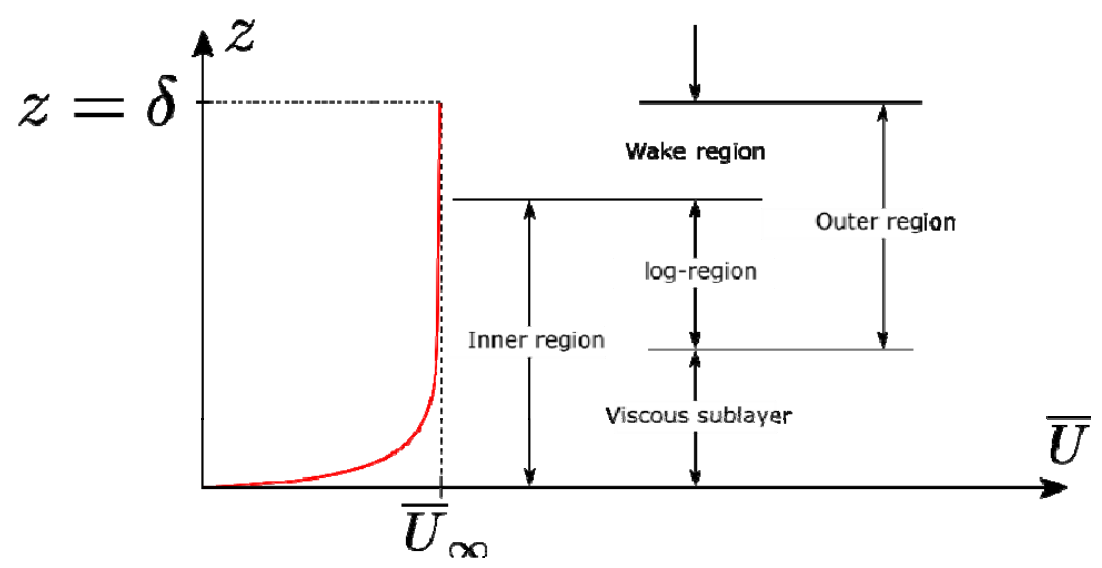

Fig. 3. Structure of turbulent boundary layers.

The measurements were conducted in the inner region of the boundary layer (viscous sublayer and logarithmic region). The logarithmic region is the overlapping zone between the inner and the outer region. In the inner region, the viscosity influences the flow and skin-friction can be directly measured with flush-mounted hot-film or estimated with the Clauser chart method. Eq. (3) shows the relation between the stream-wise velocity and the wall-normal position ([13]).

$$
\frac{\bar{U}}{U_{\tau}}=\frac{1}{\kappa} \ln \left(\frac{z U_{\tau}}{v}\right)+A
$$

Where $\kappa=0.384$ is the Von Karman constant and $A=4.17$ is considered as a universal constant.

\section{A. Clauser Chart Method for the Estimation of the Skin-friction Velocity}

The Clauser method [12] is useful for indirect estimation of the skin-friction velocity using the velocity profile data of the boundary layer. The method takes advantage of the relation between the stream-wise velocity $\bar{U}$ and the wall-normal position $z$ in the logarithmic region of the boundary layer (Eq. (3)). Eq. (4) shows the definition of the skin-friction velocity as a form to re-write the wall-shear stress in velocity units.

$$
U_{\tau} \equiv \sqrt{\frac{\tau_{w}}{\rho}}=\sqrt{v\left(\frac{d u}{d z}\right)_{z=0}}
$$

Using the definition of the friction coefficient ([14]) shown in Eq. (5), and replacing it in Eq. (3), the skinfriction velocity can be expressed in terms of $C_{f}$ and $U_{\infty}$ (Eq. (6)).

$$
\begin{gathered}
\mathbf{C}_{\mathrm{f}}=\frac{\boldsymbol{\tau}_{\mathrm{w}}}{\frac{1}{2} \rho \mathbf{U}_{\infty}^{2}} \\
\mathbf{U}_{\tau}=\sqrt{\frac{\mathbf{C}_{\mathrm{f}}}{2} \mathbf{U}_{\infty}}
\end{gathered}
$$

According to [15], by replacing (6) in (3):

$$
\frac{\bar{U}}{U_{\infty}}=\frac{1}{\kappa} \sqrt{\frac{C_{f}}{2}} \ln \left(\frac{z U_{\infty}}{v}\right)+\frac{1}{\kappa} \sqrt{\frac{C_{f}}{2}} \ln \left(\sqrt{\frac{C_{f}}{2}}\right)+\sqrt{\frac{C_{f}}{2}} A
$$

The left-hand side of Eq. (7) is the measured velocity profile of the boundary layer $\bar{U}$, normalized w.r.t. the free-stream velocity. For the right-hand side, all the variables are known except for the friction coefficient. The process consists of finding the value for $C_{f}$, which satisfies Eq. (7). Fig. 4 presents a diagram of the method. 


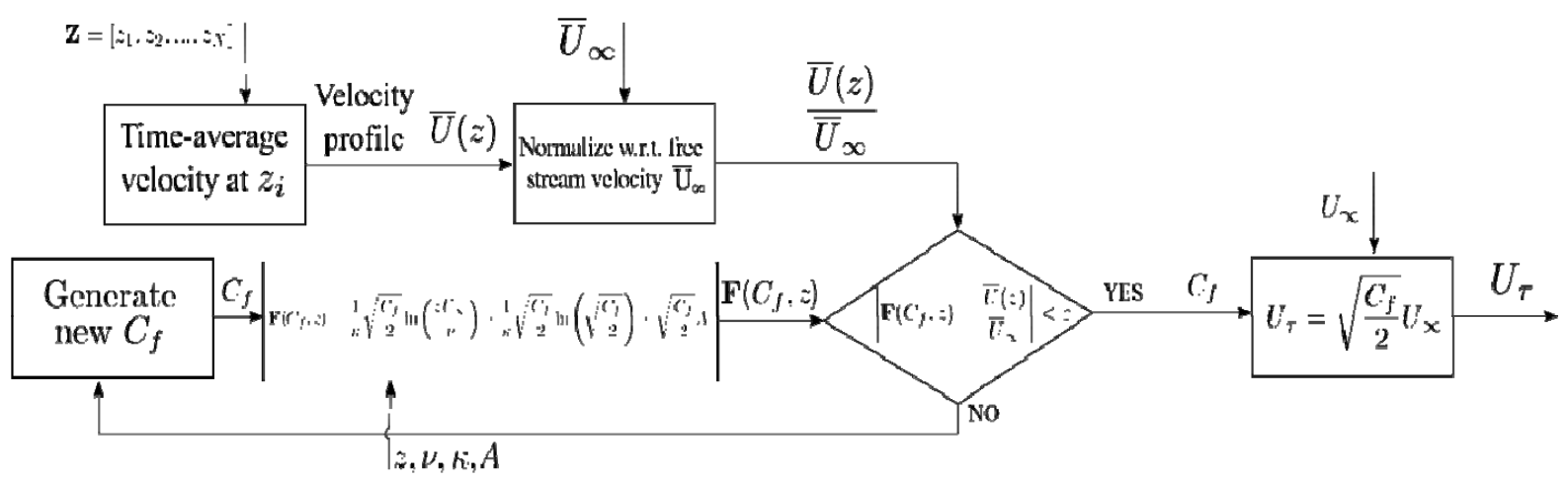

Fig. 4. Estimation of Skin Friction Velocity $U_{\tau}$ using the Clauser method ([12]). $\varepsilon$ : Convergence Threshold. $z$ : Measurement points within the boundary layer.

\section{B. Particle Image Velocimetry}

The method consists of adding tracing particles into the flow. A selected area is illuminated with a laser sheet, and one or several cameras take images of the area. The images are post-processed in a PIV package generating the displacement vector by auto- and cross-correlation methods.

1) Experimental Set-up: Fig. 5 presents the section where all measurements are carried on and the PIV measurements set-up. All the measurements are executed $21 \mathrm{~m}$ from the start of the test section as pointed in Fig. 5.

The location of the FOV origin $\left(O_{F O V}\right)$ is approximately $21 \mathrm{~m}$ from the test section start. Table V summarizes the variables in the experiment. Rows 4 and 5 exhibit an approximation of the dimensions of the FOV.

TABLE V. Experiment Variables for the PIV Measurement.

\begin{tabular}{|c|c|c|c|}
\hline & Variable & Value & Observation \\
\hline $\mathbf{1}$ & $\delta$ & $0.32 \mathrm{~m}$ & Boundary layer thickness \\
\hline $\mathbf{2}$ & $U_{\infty}$ & $20 \mathrm{~m} / \mathrm{s}$ & Free-stream velocity \\
\hline $\mathbf{3}$ & $O_{F O V}$ & $(21,0,0)$ & Location for the origin of the FOV \\
\hline $\mathbf{4}$ & $\mathrm{w}$ & $2.3 \delta$ & Width of the FOV \\
\hline $\mathbf{5}$ & $\mathrm{h}$ & $0.8 \delta$ & Height of the FOV \\
\hline
\end{tabular}

As shown in Fig. 5, An array of eight cameras $(2 \mathrm{x} 4)$ is employed. At an instant of time, the cameras take a photo, the eight images are collated into a single instantaneous snapshot Fig, 9 presents how the FOV is conformed. The snapshots are processed in an in-house (U. Melbourne) PIV package which returns a set of instantaneous vector fields of the velocity. Field discontinuities exhibited in Fig.10 appear due to the overlapping of the cameras photos and proximity to the wall.

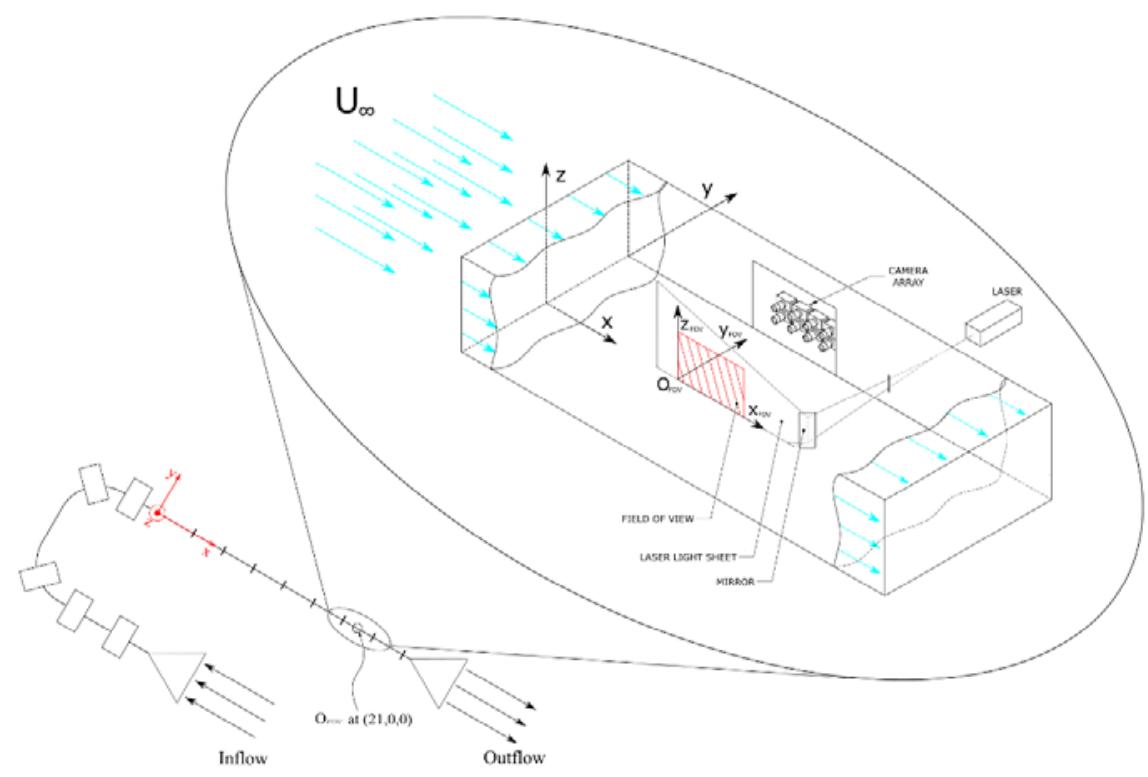

Fig. 5. Open view of the wind tunnel at the cross section where the measurements PIV, Hot-wire and 
2) Post-processing package: Because of the aim of this manuscript, the PIV post-processing package will be treated as a black box. This section presents a general notion of the inputs and outputs of the post-processing.

INPUT:

- Snapshots taken by the cameras.

- Associated coordinate system for all snapshots.

\section{OUTPUT:}

- $\quad \boldsymbol{x}:(N z \times N x)$ Matrix with $\mathrm{x}$ coordinates of the velocity field.

- $\quad z$ : $(N z \times N x)$ Matrix with z coordinates of the velocity field.

- $\boldsymbol{U}_{\text {raw }}:(N z \times N x \times N F r a m e s)$ Matrix with $U$ velocity component. Where $U_{\text {raw }}(i, j, k)$ is the stream-wise velocity at the point $(x(i, j), z(i, j))$ of the snapshot $k$.

- $W_{\text {raw }}:(N z \times N x \times N F r a m e s)$ Matrix with $W$ velocity component. Where $W_{\text {raw }}(i, j, k)$ is the wall-normal velocity at the point $(x(i, j), z(i, j))$ of the snapshot $k$.

To obtain the velocity profile of the boundary layer, it is necessary to compute two averages: (1) a temporal mean for $\boldsymbol{U}_{\text {raw }}$ and $\boldsymbol{W}_{\text {raw }}$ over the number of frames (NFrames). (2) A spatial mean over $x$ coordinate in the resulting matrices of (1). Eqs. (8) and (9) illustrate the calculation of the mean vector field and the mean velocity profile, respectively.

$$
\begin{gathered}
\bar{U}_{M}=\frac{1}{\text { NFrames }} \sum_{\substack{k=1 \\
\text { WFrames }}}^{N F r a m e s} U_{\text {raw }}(:, i, k) \\
\bar{W}_{M}=\frac{1}{\text { NFrames }} \sum_{k=1}^{N x} W_{\text {raw }}(:, i, k) \\
\bar{U}=\frac{1}{N x} \sum_{j=1}^{N x} U(:, j) \\
\bar{W}=\frac{1}{N x} \sum_{j=1}^{N x} W(:, j)
\end{gathered}
$$

\section{Hot-film Anemometry}

Hot-film and hot-wire anemometry work based on the same principle. For both techniques, the wire and the film are resistances of a circuit controlled by a Constant Temperature Anemometer (CTA) or a Constant Current Anemometer (CCA). The CTA variates the voltage, so the hot-wire or the hot-film do not change their temperature when they interact with the flow. A basic polynomial fit can describe the velocity as a function of the voltage. Section III-C-1) describes the calibration to compute the polynomial function.

For the hot-film anemometry measurement, an array of nine flush-mounted Dantec skin-friction sensors (model 55R47) are placed 21 meters downstream from the test section start. Fig. 6 shows the details of the experiment set-up and Table VI presents the variables and conditions for the experiment. Table IV presents the dimensions and material of the hot-film.

TABLE VI. Experiment Conditions for the Hot-film Measurement.

\begin{tabular}{|c|c|c|c|}
\hline & Variable & Value & Observation \\
\hline $\mathbf{1}$ & $\delta$ & $0.32 \mathrm{~m}$ & Boundary layer thickness \\
\hline $\mathbf{2}$ & $U_{\infty}$ & $15 \mathrm{~m} / \mathrm{s}$ & Free-stream velocity \\
\hline $\mathbf{3}$ & $x_{m}$ & $21 \mathrm{~m}$ & $x$ coord. of measurement point \\
\hline $\mathbf{4}$ & $\Delta f$ & $4 \mathrm{kHz}$ & Sampling frequency \\
\hline $\mathbf{5}$ & $t_{s}$ & $40 \mathrm{~s}$ & Sampling time \\
\hline $\mathbf{6}$ & $R e_{\tau}$ & 10000 & Friction Reynolds number \\
\hline
\end{tabular}




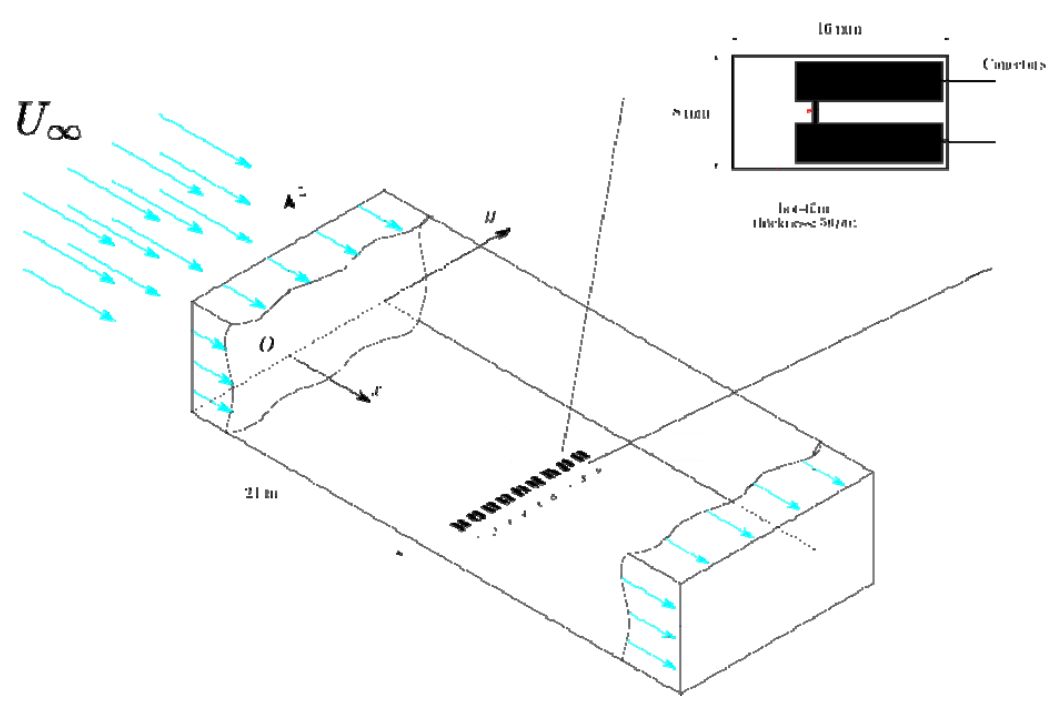

Fig. 6. Hot-film sensors set-up in the HRNBLWT. Sensor $s_{5}$ located at $y=0$.

The method consists of adding tracing particles into the flow. A selected area is illuminated with a laser sheet, and one or several cameras take images of the area. The images are post-processed in a PIV package generating the displacement vector by auto- and cross-correlation methods.

1) Calibration: The hot-films are calibrated against the free-stream velocity measured with a Pitot tube at $z=$ $0.525 \mathrm{~m}$ (outside the boundary layer). The kinematic viscosity is calculated from atmospheric conditions measured in the experiment. A transfer function based on previous skin-friction data via floating element ([16],[8]) transforms the measured $U_{\infty}$ to $U_{\tau}$.

Hot-film sensors are calibrated in-situ (i.e. the measurement data works as calibration data). The voltage and temperature of the sensors are recorded ten times for each $U_{\infty}$. Five free-stream velocities $U_{\infty}$ were chosen (seeTable VII). A total of 50 points were used for the calibration of the hot-films. Using the fit function from Matlab, the polynomial surfaces depend on the temperature of the flow and voltage of the sensor $U_{\tau}=f(T, E)$.

TABLE VII. Free-stream velocities for the hot-film calibration. $\boldsymbol{U}_{\infty}=15$ is the measurement velocity. Units in $\mathrm{m} / \mathrm{s}$.

\begin{tabular}{|l|lllll|}
\hline$U_{\infty}:$ & 12 & 13.5 & 15 & 16.5 & 18 \\
\hline
\end{tabular}

The error of the calibration is calculated as a relative error between the measured skin-friction and the value in the polynomial surface at the same temperature and voltage. A mean relative error is executed for the 50 points in each sensor and the results are shown in Fig. 14.

$$
\frac{\left|U_{\tau}(T, E)-U_{\tau m}\right|}{U_{\tau m}} \times 100
$$

Where $U_{\tau \mathrm{m}}$ is the measured skin-friction velocity and $U_{\tau}$ is the friction velocity from the surface fitting. Each sensor can measure the skin-friction independently. The sensor with the lower relative error will be used to measure the skin-friction.

\section{Hot-wire Anemometry}

Two hot-wire measurements were executed at two different free stream velocities. Fig. 7 presents the experimental set-up for the measurements. Since the probe can be moved in $\mathrm{z}$ direction, it is possible to obtain the velocity profile within the boundary layer. The probe acquires data during a determined sampling time $t_{s}$ and moves to the next established measurement point. After obtaining the velocity profile, the Clauser chart method is applied to determine the skin-friction velocity. Fig. 17 presents the results for the estimation. 


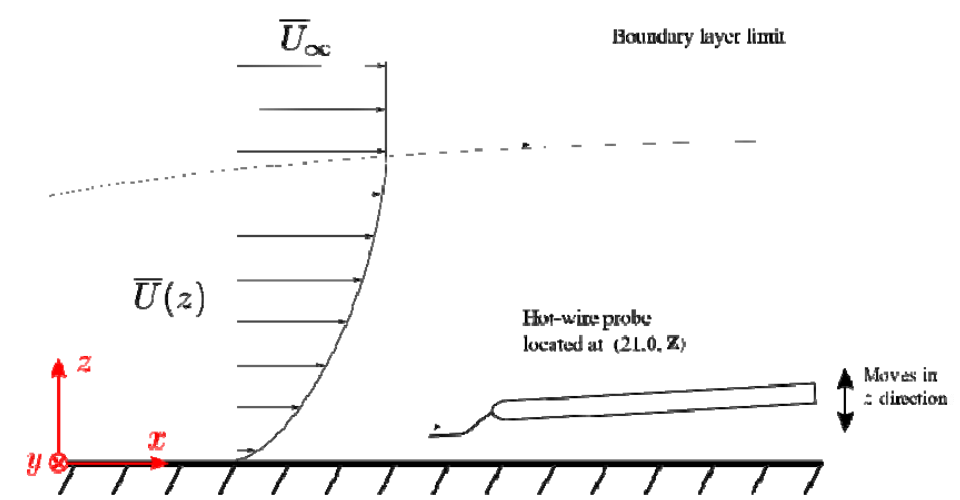

Fig. 7. Scheme of hot-wire measurement conducted in the HRNBLWT of Melbourne University. Probe moves in $x$ and $z$ directions.

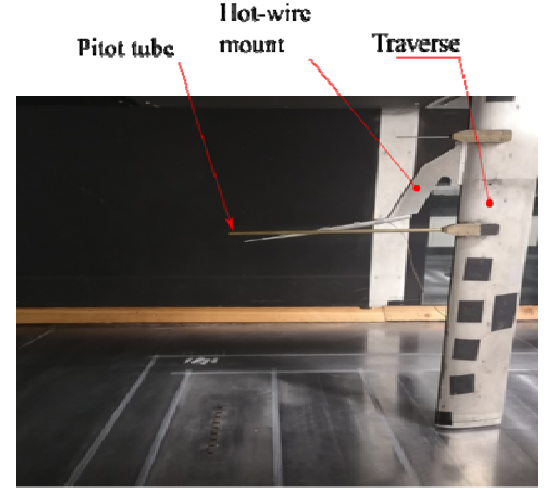

Flow

(a) Hot-wire mounted traverse

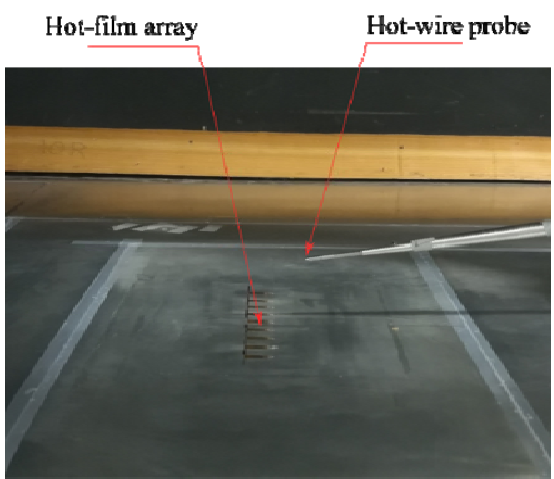

Flow

(b) Zoomed view of the hot-film set-up

Fig. 8. Hot-wire and hot-film mounted in facility. Pictures taken in the HRNBLWT of Walter Bassett Aerodynamics Laboratory in Melbourne University.

Fig. 8 presents photographs of the hot-wire and hot-film set-up in the wind tunnel. The traverse moves in $\mathrm{x}$ direction and the mount moves in $z$. Table VIII reviews the variables for both experiments. The probe measures stream-wise velocity at the defined $\boldsymbol{Z}$ points (40 points for measurement 1 and 50 for measurement 2). Row 4 defines the limits for the measurement points.

TABLE VIII. Experiment Variables for the Hot-wire Measurements.

\begin{tabular}{|c|c|c|c|}
\hline & Variable & Measurement 1 & Measurement 2 \\
\hline $\mathbf{1}$ & $\delta$ & $0.32 \mathrm{~m}$ & $0.32 \mathrm{~m}$ \\
\hline $\mathbf{2}$ & $U_{\infty}$ & $20 \mathrm{~m} / \mathrm{s}$ & $15 \mathrm{~m} / \mathrm{s}$ \\
\hline $\mathbf{3}$ & Probe position & $(21 \mathrm{~m}, 0, \mathbf{Z})$ & $(21 \mathrm{~m}, 0, \mathbf{Z})$ \\
\hline $\mathbf{4}$ & $\mathbf{Z}$ & $(0.3 \leq \mathrm{z} \leq 525) \mathrm{mm}$ & $(0.2 \leq \mathrm{z} \leq 500) \mathrm{mm}$ \\
\hline $\mathbf{5}$ & $\Delta \mathrm{f}$ & $20 \mathrm{kHz}$ & $20 \mathrm{kHz}$ \\
\hline $\mathbf{6}$ & $t_{s}$ & $360 \mathrm{~s}$ & $40 \mathrm{~s}$ \\
\hline $\mathbf{7}$ & $R e_{\tau}$ & 14000 & 10000 \\
\hline
\end{tabular}

1) Calibration: Hot-wire anemometry requires pre- and post- calibration, forces, temperature, and other perturbations during the measurement could alter the hot-wire accuracy. Pre- and post- calibration were conducted at $z=0.525 \mathrm{~m}$ against 16 free-stream velocities from 0 to $24 \mathrm{~m} / \mathrm{s}$. A third-order polynomial was fitted for both sets of calibration data (Eq. (11)).

$$
\begin{aligned}
& C_{\text {pre }}=a_{3} E^{3}+a_{2} E^{2}+a_{1} E+a_{0} \\
& C_{\text {post }}=b_{3} E^{3}+b_{2} E^{2}+b_{1} E+b_{0}
\end{aligned}
$$

Using both calibration curves is possible to interpolate a "measurement curve" $\left(C_{m}\right)$ as a mid-point of both curves coefficients (Eq. (12)). The resultant curve and the data acquired during the measurement (voltage) are used to determine the stream-wise velocity. 


$$
C_{m}=\frac{1}{2}\left[\left(a_{3}+b_{3}\right) E^{3}+\left(a_{2}+b_{2}\right) E^{2}+\left(a_{1}+b_{1}\right) E+\left(a_{0}+b_{0}\right)\right]
$$

\section{Results}

\section{A. Particle Image Velocimetry}

After obtaining the velocity fields from the PIV post-processing package, 733 instantaneous snapshots were obtained. Fig 9 illustrates an approximated division of the FOV. Each camera takes a portion $C_{i}$ of the FOV. Then, the images are collated together to produce a snapshot. Fig. 10 presents one of the instantaneous snapshots for stream-wise and wall-normal velocity.

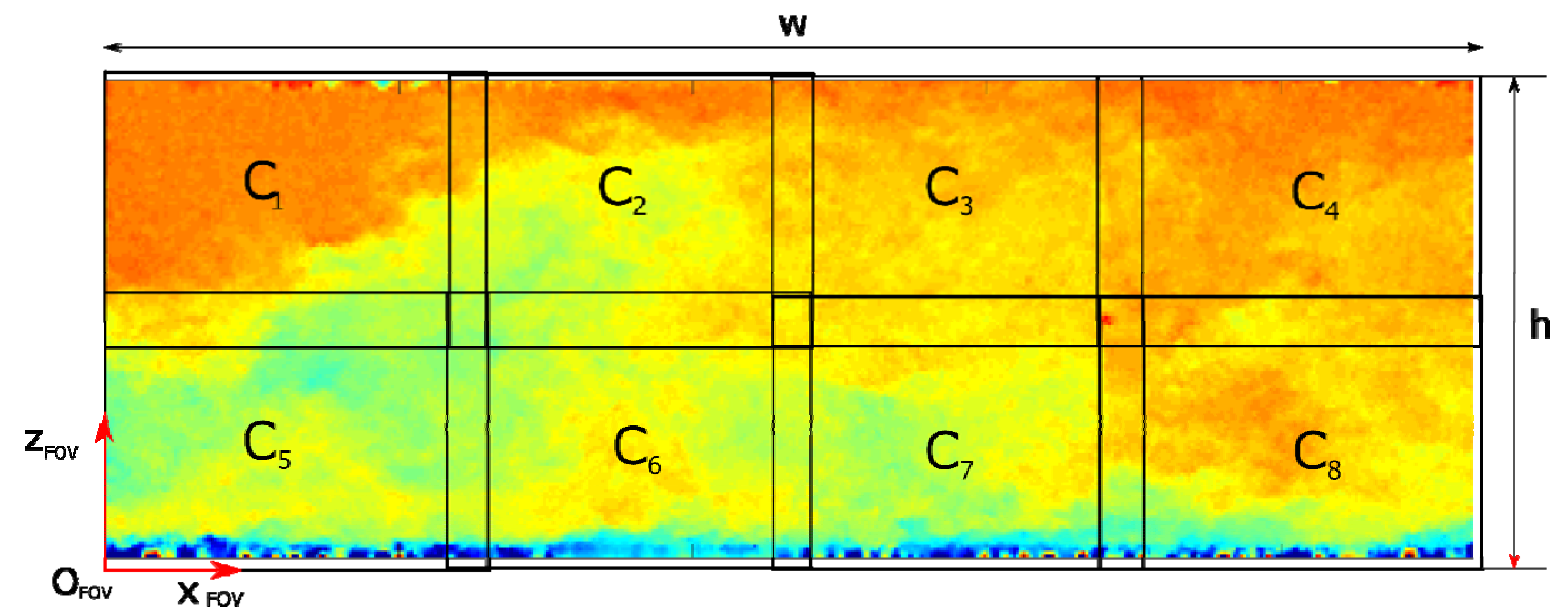

Fig. 9. Snapshot division example. There are overlapping zones where distortions might appear.

The fields $\overline{\boldsymbol{U}}_{\boldsymbol{M}}$ and $\overline{\boldsymbol{W}}_{\boldsymbol{M}}$ resulting from appliying Eq. (8), with NFrames $=733$ are shown in Fig. 11. The stream-wise velocity presents a clear and sooth increasing as it is farther from the wall. Mean wall-normal velocity $\overline{\boldsymbol{W}}_{\boldsymbol{M}}$ has insignificant magnitude compared to $\overline{\boldsymbol{U}}_{\boldsymbol{M}}$.

For the velocity profile, the spatial mean was calculated with Eq. (9) for the stream-wise component. Obtaining the profile in Fig. 12.

1) Clauser Chart and Skin-friction: Fig 12b presents the estimation of the skin-friction velocity by using the Clauser method. Different values of $C_{f}$ were tested. With a $C_{f}=2.076 \times 10^{-3}$, the value of the skin-friction is $U_{\tau}=0.671 \mathrm{~m} / \mathrm{s}$.

In Fig. 12b, the blue data is the spatial mean scaled by the free stream velocity. Black lines are curves for different skin friction coefficient values. After obtaining the skin friction velocity, is possible to scale the mean stream-wise velocity $\bar{U}$ and the wall-normal position $z$ to obtain the boundary layer mean profile in adimensional quantities (Fig. 12c). The data complies with the logarithmic rule of the boundary layer.
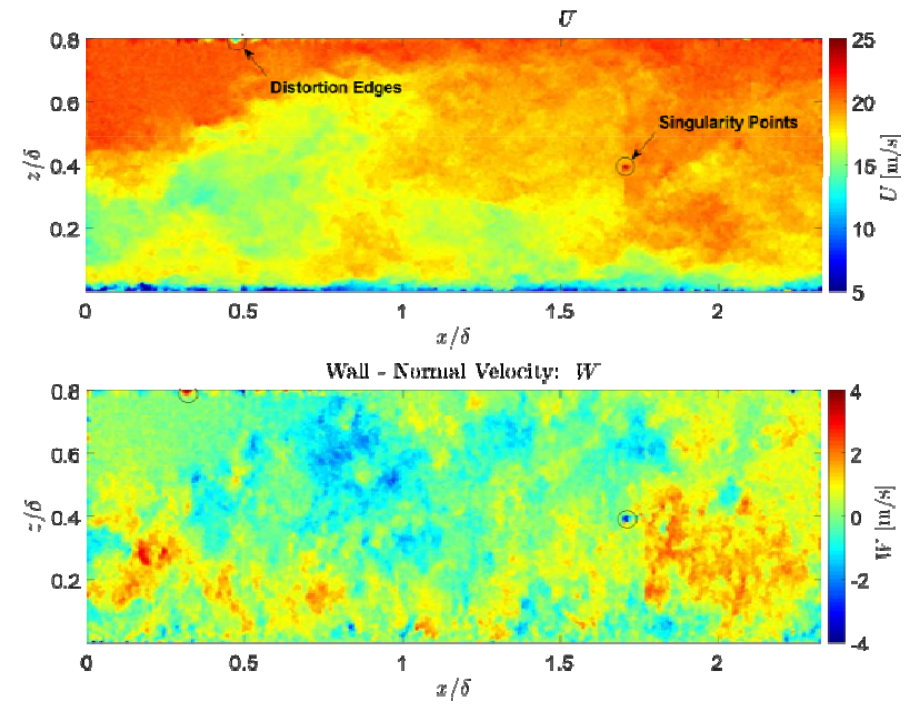

Fig. 10. Raw data from PIV package. Field discontinuities might appear because of overlapping images and wall proximity. 
(a) Streamwise Velocity average: $\bar{U}$

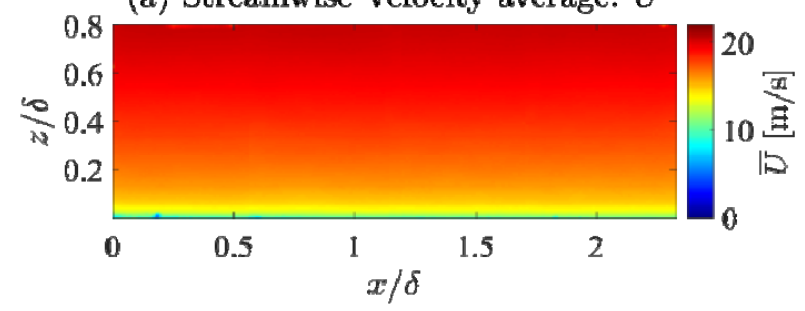

(b) Wall - Normal Velocity average: $\bar{W}$

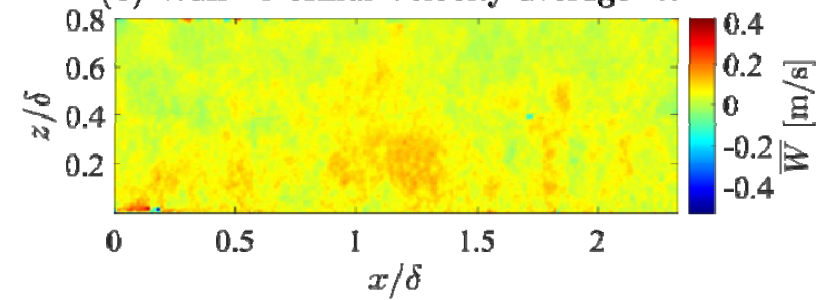

(c) Wall - Normal Velocity average: $\bar{W}$

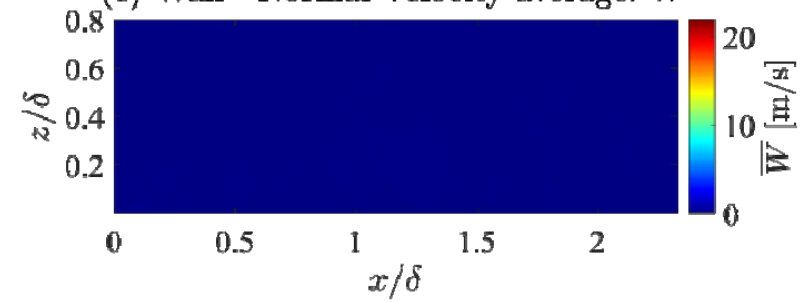

Fig. 11. (a): Stream-wise mean velocity field. (b) and (c): Wall-normal velocity mean field with different scalar maps.

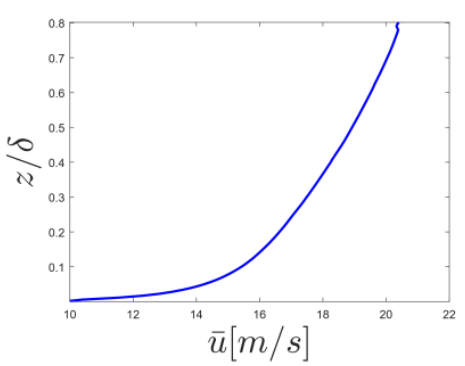

(a)

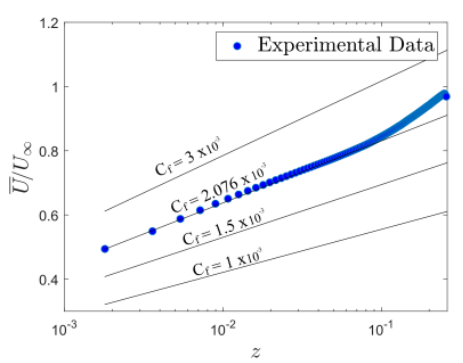

(b)

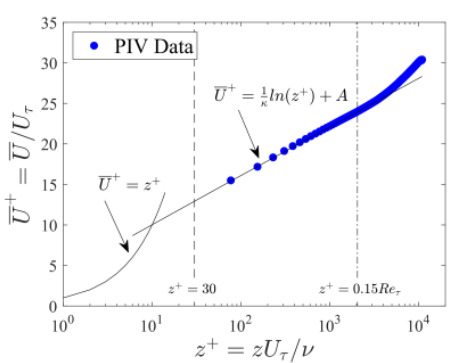

(c)

Fig. 12. (a): Velocity profile of boundary layer, (b) Clauser chart method and (c) stream-wise velocity scaled by the friction velocity $U_{\tau}$. Data at $U_{\infty}=20$.

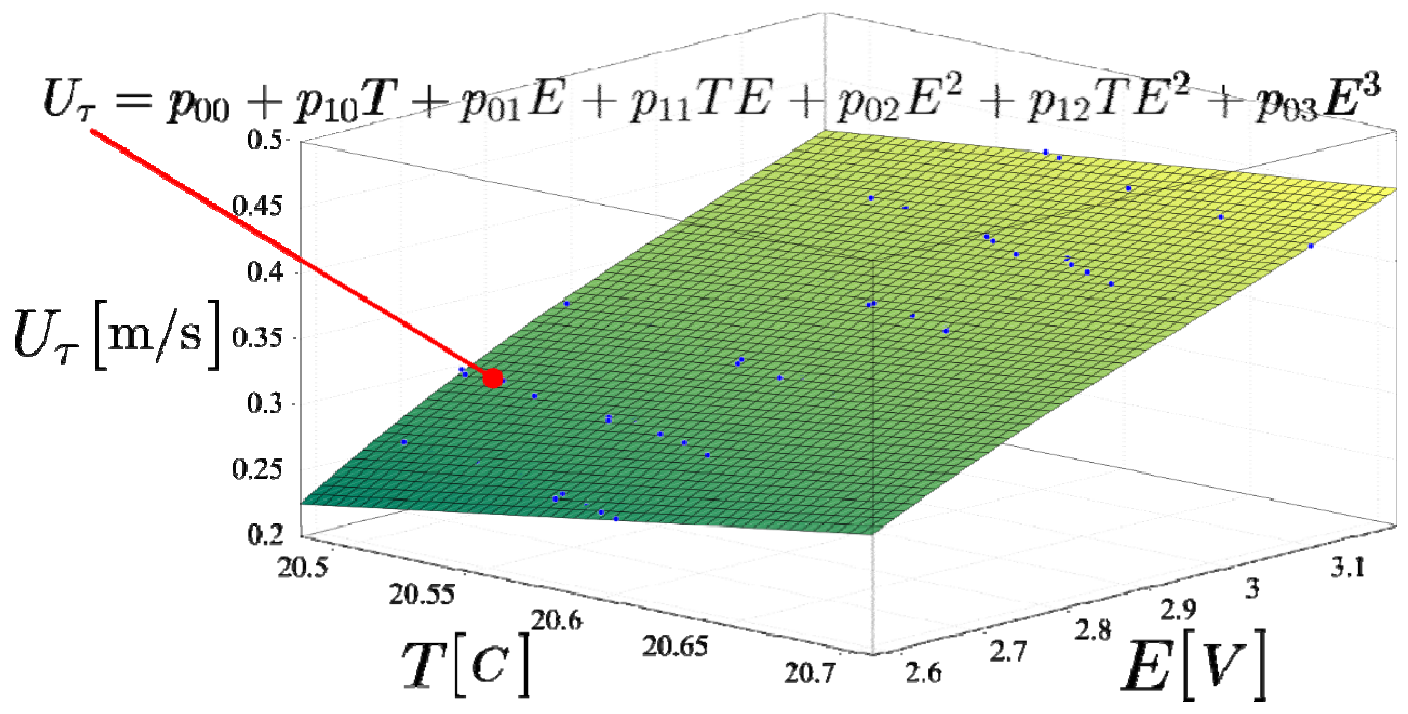

Fig. 13. One-degree and third-degree polynomial surface fit for the temperature and the voltage, respectively. 


\section{B. Hot-film Anemometry}

Five polynomial surfaces were tested. Figs. 13 and 14 show one of the fitting surfaces evaluated in the sensor $s_{4}$ and the relative errors for all the fittings in all the sensors, respectively.

The values of the coefficients for the surface are: $p_{00}=-31.17 p_{10}=1.15 p_{01}=15.68 p_{11}=$ $-0.45 \mathrm{p}_{02}=-2.78 \mathrm{p}_{12}=0.05 \mathrm{p}_{03}=0.18$ with $95 \%$ confidence bounds.

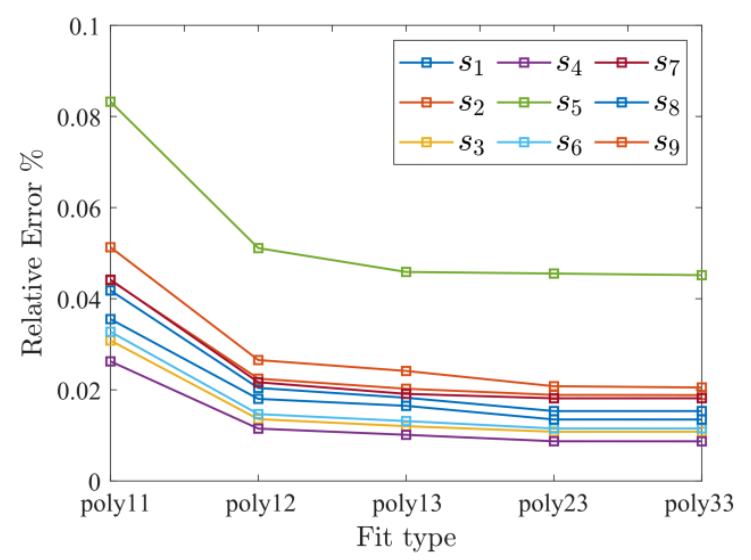

Fig. 14. Mean of the relative error for each surface fitting tried.

The error in Fig. 14 decreases significantly after increasing the degree for the voltage. After 'poly13' fitting type, there is no considerable change in the error. Sensor $s_{4}$ presents the lower value for relative error in all the fitting surfaces, this sensor is chosen to calculate the skin-friction.

Using the polynomial fitting with 1-degree and 3-degree for $T$ and $E$, respectively, the skin-friction velocity at $U_{\infty}=15 \mathrm{~m} / \mathrm{s}$ can be calculated with (13)

$$
\bar{E}_{4}=3.2006 \mathrm{~V}, \bar{T}=21.022 C, U_{\tau}(\bar{T}, \bar{E})=0.4934 \mathrm{~m} / \mathrm{s}
$$

Where $\bar{T}$ and $\bar{E}_{4}$ are the averaged temperature and voltage at $U_{\infty}=15 \mathrm{~m} / \mathrm{s}$. The sub-index indicates the sensor used.

\section{Hot-wire Anemometry}

Fig. 15 shows the calibration curves for the hot-wire anemometry. The curves present a notable offset after a velocity of $5 \mathrm{~m} / \mathrm{s}$.

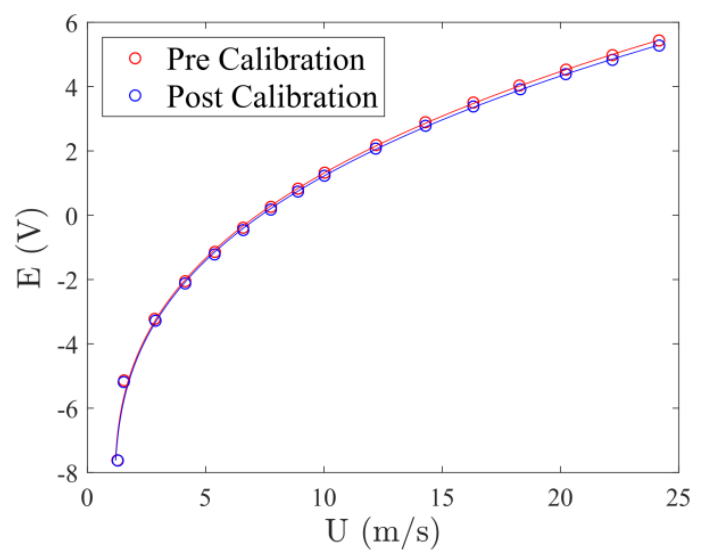

Fig. 15. Pre- and post- calibration curves for hot-wire. 
Table IX presents the coefficients for both curves and the interpolated curve for the measurement.

TABLE IX. Curves Coefficient for the Calibration of the Hot-wire.

\begin{tabular}{|c|c|c|c|}
\hline & Pre & Post & Interpolation \\
\hline$a_{3}$ & 0.006 & 0.007 & 0.006 \\
\hline$a_{2}$ & 0.19 & 0.2 & 0.2 \\
\hline$a_{1}$ & 1.88 & 1.93 & 1.91 \\
\hline$a_{0}$ & 7.187 & 7.34 & 7.26 \\
\hline
\end{tabular}

Therefore, the calibration curve is:

$$
C_{m}=U(E)=0.006 E^{3}+0.2 E^{2}+1.91 E+7.26
$$

Eq. (14) is used in the measurement data to find the mean profile of the boundary layer. Fig. 16 presents the scaled profile and compared with the PIV measurement. Due to spatial resolution and logarithmically spaced points, hot-wire anemometry can measure closer to the wall.

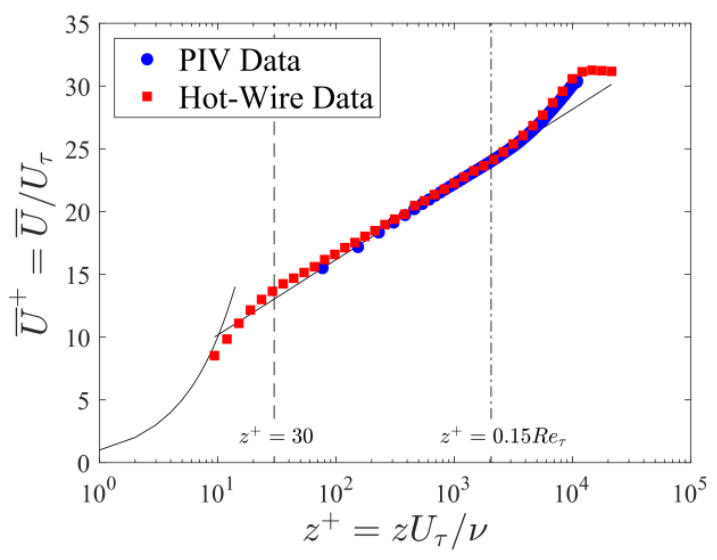

Fig. 16. Hot-wire and PIV data velocity profiles. $U_{\infty}=20 \mathrm{~m} / \mathrm{s}$.

1) Clauser Chart for Hot-wire: The same way it was executed in section IV-A-1) , Fig. 17 presents the fitted $C_{f}$ to estimate the skin-friction velocity.

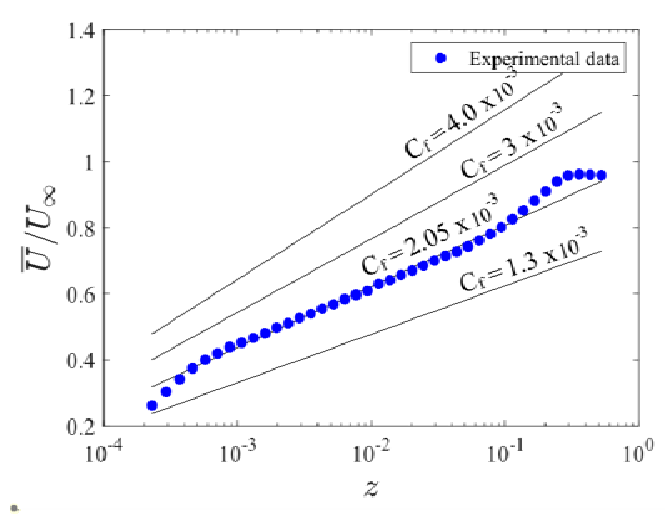

(a)

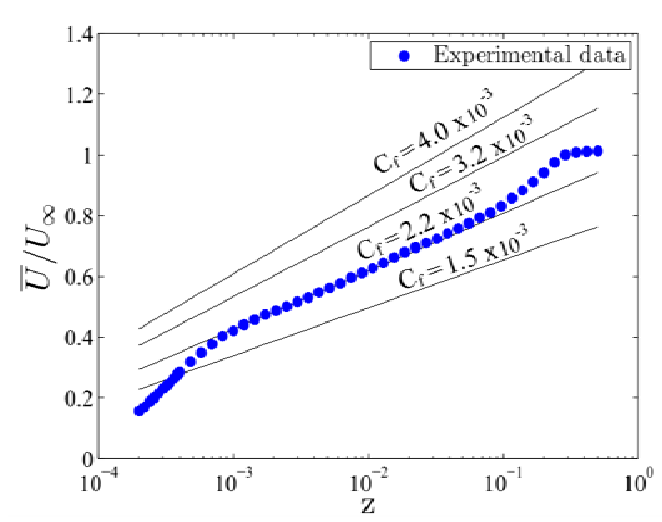

(b)

Fig. 17. Clauser charts of hot-wire measurement. (a): $U_{\infty}=20 \mathrm{~m} / \mathrm{s}$ (b): $U_{\infty}=15 \mathrm{~m} / \mathrm{s}$.

Fig. 17a, with a $C_{f}=2.05 \times 10^{-3}$, applying Eq. (6), the value for the skin-friction velocity is $U_{\tau}=0.6671 \mathrm{~m} / \mathrm{s}$ and from Fig, $17 \mathrm{~b}$ and a $C_{f}=2.2 \times 10^{-3}$, the value for the skin-friction velocity is $U_{\tau}=0.4998 \mathrm{~m} / \mathrm{s}$.

2) Measurements Summary: Table $X$ summarizes all the obtained values of the skin-friction in the measurements. 
TABLE X. Summary of Calculated Skin-friction Velocity $\boldsymbol{U}_{\boldsymbol{\tau}}$ (units in $\mathrm{m} / \mathrm{s}$ ).

\begin{tabular}{|c|c|c|c|}
\hline $\boldsymbol{U}_{\infty} \mathbf{~ m} / \mathbf{s}$ & Hot-film & Hot-wire & PIV \\
\hline $\mathbf{1 5}$ & 0.4934 & 0.4998 & N/A \\
\hline $\mathbf{2 0}$ & N/A & 0.6671 & 0.671 \\
\hline
\end{tabular}

\section{CONCLUSIONS AND FUTURE WORK}

Three different measurement techniques were presented, PIV, hot-wire and hot-film anemometry. The methods present consistent results in the estimation of the skin-friction velocity since the values of the calculated skin-friction velocity had low relative errors $(\approx 1.29 \%)$. The Clauser chart mainly depends on the reliable measurement of the velocity profile of the boundary layer.

PIV presents the highest computational cost due to the amount of data to be processed. Since the points in $z$ were not logarithmically spaced, there was a low resolution closer to the wall. However, the technique is accurate and could be improved by using high resolution and high magnification cameras. PIV provides a larger field of view than the constant temperature anemometers. Flush mounted hot-film anemometry cannot measure the boundary layer profile but directly measures the instantaneous skin-friction velocity and therefore, its fluctuations. Moreover, they do not depend on the velocity profile.

Future work is required in the assessment of directly measuring skin-friction very close to the wall (viscous sublayer) with hot-wire and PIV. Also, evaluate the accuracy of each technique at different Reynolds numbers.

\section{ACKNOWLEDGMENT}

We especially thank Professor Ivan Marusic and Professor Nickolas Hutchins, members of Walter Bassett Aerodynamics Laboratory at The University of Melbourne, which provided the facilities, expertise and supervision during the research.

\section{REFERENCES}

[1] D. Sturzebecher, S. Anders, and W. Nitsche, "The surface hot wire as a means of measuring mean and actuating wall shear stress," Experiments in Fluids, vol. 31, pp. 294-301, 092001.

[2] M. A. Ferreira, E. Rodriguez-Lopez, and B. Ganapathisubramani, "An alternative floating element design for skin-friction measurement of turbulent wall flows," Experiments in Fluids, vol. 59, no. 10, p. 155, 2018.

[3] M. Abbassi, W. Baars, N. Hutchins, and I. Marusic, "Skin-friction drag reduction in a high-reynolds number turbulent boundary layer via real-time control of large-scale structures," International Journal of Heat and Fluid Flow, vol. 67, pp. 30-41, 2017.

[4] B. Blocken, T. Stathopoulos, and J. Van Beeck, "Pedestrian-level wind conditions around buildings: Review of wind-tunnel and CFD techniques and their accuracy for wind comfort assessment," Building and Environment, vol. 100, pp. 50-81, 2016.

[5] E. Rodriguez-Lopez, P. J. Bruce, and O. R. Buxton, "A robust post-processing method to determine skin friction in turbulent boundary layers from the velocity profile," Experiments in Fluids, vol. 56, no. 4, p. 68, 2015.

[6] C. De Silva, E. Gnanamanickam, C. Atkinson, N. Buchmann, N. Hutchins, J. Soria, and I. Marusic, "High spatial range velocity measurements in a high reynolds number turbulent boundary layer," Physics of fluids, vol. 26, no. 2, p. 025117, 2014.

[7] N. Hutchins and K.-S. Choi, "Accurate measurements of local skin friction coefficient using hot-wire anemometry," Progress in Aerospace Sciences, vol. 38, no. 4-5, pp. 421-446, 2002.

[8] R. Abbassi, "Drag reduction via manipulation of large-scale coherent structures in a high reynolds number turbulent boundary layer," Ph.D. dissertation, The University of Melbourne, 2018.

[9] W. Harbison and H. Petrie, "Evaluation of flush-mounted hot-film sensors for skin friction reduction measurements in viscoelastic polymer solutions," Experiments in Fluids, vol. 11, no. 4, pp. 243-246, 1991.

[10] I. Marusic, K. Talluru, and N. Hutchins, "Controlling the large-scale motions in a turbulent boundary layer," in Fluid-Structure-Sound Interactions and Control. Springer, 2014, pp. 17-26.

[11] Thermopedia, "Hot-wire and hot-film anemometers," Feb 2011. [Online]. Available: http://www.thermopedia.com/content/853/

[12] F. H. Clauser, "Turbulent boundary layers in adverse pressure gradients," Journal of the Aeronautical Sciences, vol. 21, no. 2, pp. 91108, 1954.

[13] T. Von Karman, "Mechanical similitude and turbulence," National Advisory Committee on Aeronautics, Tech. Rep., 1930.

[14] H. Schlichting and K. Gersten, Boundary-layer theory. Springer, 2016.

[15] T. Wei, R. Schmidt, and P. McMurtry, "Comment on the Clauser chart method for determining the friction velocity," Experiments in fluids, vol. 38, no. 5, pp. 695-699, 2005.

[16] W. Baars, D. Squire, K. Talluru, M. Abbassi, N. Hutchins, and I. Marusic, "Wall-drag measurements of smooth- and rough-wall turbulent boundary layers using a floating element," Experiments in Fluids, vol. 57, no. 5, p. 90, 2016.

[17] J. D. Anderson, "Ludwig Prandtl boundary layer," Physics Today, vol. 58, no. 12, pp. 42-48, 2005.

[18] N. Hutchins and I. Marusic, "Evidence of very long meandering features in the logarithmic region of turbulent boundary layers," Journal of Fluid Mechanics, vol. 579, pp. 1-28, 2007.

[19] R. Thibault and G. J. Poitras, "Uncertainty evaluation of friction velocity measurements by oil-film interferometry," Journal of Fluids Engineering, vol. 139, no. 5, p. 051401, 2017.

[20] S. Rezaeiravesh, R. Vinuesa, M. Liefvendahl, and P. Schlatter, "Assessment of uncertainties in hot-wire anemometry and oil-film interferometry measurements for wall-bounded turbulent flows," European Journal of Mechanics-B/Fluids, vol. 72, pp. 57-73, 2018.

[21] F. Durst, H. Kikura, I. Lekakis, J. Jovanovic, and Q. Ye, "Wall shear stress determination from near-wall mean velocity data in turbulent pipe and channel flows," Experiments in Fluids, vol. 20, no. 6, pp. 417-428, Apr 1996. [Online]. Available: https://doi.org/10.1007/BF00189380

[22] P. Freymuth, "Frequency response and electronic testing for constant-temperature hot-wire anemometers," Journal of Physics E: Scientific Instruments, vol. 10, no. 7, p. 705, 1977.

[23] C. M. de Silva, K. Grayson, S. Scharnowski, C. J. Kahler, N. Hutchins, and I. Marusic, "Towards fully-resolved PIV measurements in high reynolds number turbulent boundary layers with DSLR cameras," Journal of Visualization, vol. 21, no. 3, pp. 369-379, 2018. 
[24] M. Raffel, C. E. Willert, F. Scarano, C. J. Kahler, S. T. Wereley, and J. Kompenhans, Particle image velocimetry: a practical guide. Springer, 2018.

[25] M. K. Talluru, "Manipulating large-scale structures in a turbulent boundary layer using a wall-normal jet," Ph.D. dissertation, The University of Melbourne, 2013.

[26] D. Chong, "Lecture bl13: Resistance laws," Lecture notes MCEN90018 Advanced Fluid Dynamics, May 2017, Melbourne University School of Engineering.

[27] D. Dynamics, "Glue-on probe for air," Nov 2019. [Online]. Available: https://www.dantecdynamics.com/glue-on-probe-for-air

\section{AUTHOR PROFILE}

Cristian Rendon-Cardona is a senior-year student of Mechanical Engineering at EAFIT University. Since 07-2017, Cristian has been research assistant and several times Grader and Workshop Instructor for the course on Introduction to CAD CAM Systems in the Laboratory of CAD CAM CAE at U. EAFIT under the supervision of Prof. Oscar Ruiz-Salguero. In the first semester of 2019, Cristian conducted a Research Internship in the Walter Bassett Aerodynamics Laboratory at Melbourne University. His interests are in Dynamic Systems, Computational Fluid Dynamics and Computational Mechanics.

Zhoushun Ruan is currently in his last year of $\mathrm{PhD}$ at The University of Melbourne under the supervision of Professor Ivan Marusic and Professor Nickolas Hutchins in the field of turbulent boundary layer and flow control.

Oscar Ruiz-Salguero obtained Diplomas in Mechanical Eng. and Computer Science at. U. de los Andes Colombia, and a M.Sc. - Ph.D. (1995) from U. Illinois at Urbana- Champaign, USA. Prof. Ruiz - Salguero has held Visiting Researcher positions at Ford Motor Co. (USA), Fraunhofer Inst. for Computer Graphics (Germany), University of Vigo (Spain), Max Planck Inst. for Informatik (Germany) and Purdue University (USA). He is coordinator of the CAD CAM CAE Laboratory at U. EAFIT (Colombia). His research interests are in Applied Computational Geometry. 